\title{
Role of Reactive Oxygen Species in Reperfusion Injury of the Rabbit Lung
}

Thomas P. Kennedy, N. V. Rao, Christopher Hopkins, Larry Pennington, Elizabeth Tolley, and John R. Hoidal

Division of Pulmonary Medicine, Department of Medicine, and Department of Epidemiology, University of Tennessee Center for Health Sciences, Memphis, Tennessee 38163; and Division of Transplantation Surgery, Department of Surgery,

University of Oklahoma Health Sciences Center, Oklahoma City, Oklahoma 73190

\begin{abstract}
We have developed a model of reperfusion injury in Krebs buffer-perfused rabbit lungs, characterized by pulmonary vasoconstriction, microvascular injury, and marked lung edema formation. During reperfusion there was a threefold increase in lung superoxide anion $\left(O_{\bar{z}}\right)$ production, as measured by in vivo reduction of nitroblue tetrazolium, and a twofold increase in the release of $\mathrm{O}_{\dot{i}}^{\bar{i}}$ into lung perfusate, as measured by reduction of succinylated ferricytochrome $c$. Injury could be prevented by the xanthine oxidase inhibitor allopurinol, the $\mathbf{O}_{\bar{i}}^{\bar{z}}$ scavenger SOD, the hydrogen peroxide scavenger catalase, the iron chelator deferoxamine, or the thiols dimethylthiourea or $\mathbf{N}$ acetylcysteine. The protective effect of SOD could be abolished by the anion channel blocker $4,4^{\prime}$-diisothiocyano-2,2'stilbene disulfonic acid, indicating that SOD consumes $O_{\overline{2}}^{-}$in the extracellular medium, thereby creating a concentration gradient favorable for rapid diffusion of $\mathrm{O}_{\dot{i}}^{-}$out of cells. Our results extend information about the mechanisms of reperfusion lung injury that have been assembled by studies in other organs, and offer potential strategies for improved organ preservation, for treatment of reperfusion injury after pulmonary thromboembolectomy, and for explanation and therapy of many complications of pulmonary embolism.
\end{abstract}

\section{Introduction}

Free radical-mediated injury is a major cause of damage occurring in ischemic tissue after reperfusion (1). Currently, reperfusion injury is thought to hinge on two critical events occurring during ischemia: degradation of cellular stores of ATP to the purines hypoxanthine and xanthine; and conversion of xanthine dehydrogenase to xanthine oxidase (1). During reperfusion, the sudden availability of oxygen to act as cofactor allows xanthine oxidase to convert purine substrate accumulated during ischemia to uric acid, with byproduct formation of superoxide anions $\left(\mathrm{O}_{\overline{2}}^{\overline{2}}\right)$ and hydrogen peroxide $\left(\mathrm{H}_{2} \mathrm{O}_{2}\right)(1,2)$. In the presence of iron, $\mathrm{O}_{\overline{2}}^{\overline{2}}$ and $\mathrm{H}_{2} \mathrm{O}_{2}$ can participate in an $\mathrm{O}_{\dot{2}}^{-}$-driven Fenton reaction to produce hydroxyl radicals $(\cdot \mathrm{OH})(3)$ :

$\mathrm{O}_{\bar{i}}^{\bar{i}}+\mathrm{Fe}^{3+} \rightarrow \mathrm{O}_{2}+\mathrm{Fe}^{2+}$

$\mathrm{Fe}^{2+}+\mathrm{H}_{2} \mathrm{O}_{2} \rightarrow \mathrm{Fe}^{3+}+\cdot \mathrm{OH}+\mathrm{OH}-$

Address reprint requests to Dr. Thomas P. Kennedy, Division of Allergy, Critical Care, and Respiratory Medicine, PO Box 3177, Duke University Medical Center, Durham, NC 27710.

Received for publication 25 February 1987 and in revised form 6 December 1988.

J. Clin. Invest.

(C) The American Society for Clinical Investigation, Inc.

0021-9738/89/04/1326/10 \$2.00

Volume 83, April 1989, 1326-1335
Hydroxyl radicals are potent oxidants that cause tissue injury by initiating lipid peroxidation of cell membranes and oxidative inactivation of critical cell proteins (3). During reperfusion, the above reactions can be stopped and injury prevented by inhibiting xanthine oxidase to prevent production of $\mathrm{O}_{\overline{2}}$ and $\mathrm{H}_{2} \mathrm{O}_{2}(1)$, scavenging $\mathrm{O}_{\overline{2}}^{\overline{2}}$ to prevent its reduction of iron $(1,4)$, chelating iron so that it is unavailable to participate in the generation of $\cdot \mathrm{OH}(5)$, or neutralizing $\cdot \mathrm{OH}$ with scavenging reagents $(6)$.

Reperfusion injury mediated by oxygen free radicals has been reported in heart (7), brain (5), intestine (8), liver (9), pancreas (10), kidney (6), and skin (11). Whereas reperfusion injury has also been reported after reexpansion of atelectatic lung (12) or reperfusion of a mechanically occluded pulmonary artery (13), investigators have generally felt that the lung is relatively immune from reperfusion injury because oxidative metabolism does not decrease and ATP levels do not fall until alveolar $\mathrm{PO}_{2}$ drops below $1 \mathrm{mmHg}$ (14). We undertook this investigation to characterize the biochemical events during reperfusion lung injury after warm ischemia. Our results indicate that the lung is susceptible to reperfusion injury. The source of this injury appears to be reactive oxygen species, such as $\mathrm{O}_{\bar{i}}$ generated during reperfusion. Our experiments also show that extracellular SOD protects against intracellular damage from toxic oxygen species by consuming $\mathrm{O}_{\dot{2}}^{-}$in the extracellular medium, thereby promoting rapid concentration-driven diffusion of $\mathrm{O}_{\overline{2}}^{\overline{2}}$ out of the intracellular compartment.

\section{Methods}

Reagents and pharmaceuticals. $N$-Acetylcysteine, allopurinol, 3,000 $\mathrm{U} / \mathrm{mg}$ catalase from bovine liver, diethyldithiocarbamate (DDC), ${ }^{1}$ 4,4'-diisothiocyano-2,2'-stilbene disulfonic acid (DIDS), $N$-ethylmaleimide (NEM), $\mathrm{FeCl}_{3}$, ferricytochrome $c$ (type VI horse heart), indomethacin, nitroblue tetrazolium (NBT), 3,200 U/mg SOD from bovine erythrocytes, and succinic anhydride were obtained from Sigma Chemical Company, St. Louis, MO. Dimethylthiourea (DMTU) was obtained from Fike Chemicals, Nitro, WV. Deferoxamine mesylate (Desferal) was obtained from Ciba-Geigy Pharmaceuticals, Summit, NJ. Reagent grade pyridine was from Fisher Chemical Company, Fair Lawn, NJ.

Lung perfusion technique. Male New Zealand white rabbits (Myrtle Farms, Nashville, TN) weighing $2.5-3 \mathrm{~kg}$ were maintained on rabbit formula (18; Carnation Co., Los Angeles, CA) and water ad lib. On the day of the experiment, the rabbits were given 3,000 $\mathrm{U}$ of heparin by ear vein and anesthetized with $25 \mathrm{mg} / \mathrm{kg}$ sodium pentobarbital. The chest was opened and the animal killed by rapid exsanguination from the left

1. Abbreviations used in this paper: CAT, catalase; DMTU, dimethylthiourea; DIDS, 4,4'-diisothiocyano-2,2'-stilbene disulfonic acid; NBT, nitroblue tetrazolium; NEM, $N$-ethylmaleimide; $P_{\mathrm{pa}}$, pulmonary artery pressure; $P_{\mathrm{pa} \mathrm{max}}$, maximal pulmonary artery pressure; $P_{\mathrm{T}}$, maximal inspiratory tracheal pressure; $\Delta \mathrm{W}$, rate of lung weight gain from edema formation. 
ventricle. Right and left parasternal incisions were made along the costal cartilages to remove the sternum and open the chest widely. Stainless steel cannulae were secured in the left atrium and pulmonary artery with umbilical tape. The ligature around the pulmonary artery was also passed around the aorta, preventing loss of perfusate into the systemic circulation. The pulmonary circulation was washed free of blood with $\sim 500 \mathrm{ml}$ of perfusate before recirculating flow was established at $50 \mathrm{ml} / \mathrm{min}$. The perfusate medium was protein-free KrebsHenseleit buffer (15) prepared with deionized water and maintained at a temperature of $37-38^{\circ} \mathrm{C}$ and $\mathrm{pH}$ of $7.35-7.40$.

The perfusion circuit included a perfusate reservoir, roller perfusion pump (Sarns, Inc., Ann Arbor, MI), filter (swank transfusion filter; Extracorporeal Medical Specialties, Inc., King of Prussia, PA), and heat exchanger, connected by Tygon tubing. The reservoir collecting perfusate from the left atrium was suspended from a force displacement transducer (model FT10D; Grass Instrument Company, Quincy, MA) so that loss of reservoir weight from lung edema formation could be continuously measured. The perfusate reservoir was placed below the lower most portion of the lung to keep left atrial pressure at zero. The volume of the perfusion system was $250 \mathrm{ml}$.

The lungs were ventilated with $5 \% \mathrm{CO}_{2}$ in air through a tracheostomy using an animal respirator (Harvard Apparatus Company, Inc., S. Natick, MA) delivering a tidal volume of $7 \mathrm{ml} / \mathrm{kg}$ at 18 breaths per minute with $2 \mathrm{~cm} \mathrm{H}_{2} \mathrm{O}$ positive end-expiratory pressure. Pulmonary arterial, left atrial, and tracheal pressures were monitored using pressure transducers (P23ID; Gould Statham Instruments, Inc., Hato Rey, PR) connected to the inflow circulation, outflow circulation, and tracheal cannula. Pressure and force transducer measurements were recorded on a four-channel recorder (model 2400S; Gould Statham Instruments, Inc.). Successful preparations with initial pulmonary artery pressures between 8 and $15 \mathrm{mmHg}$ and weight gain at rates of $<0.2$ $\mathrm{g} / \mathrm{min}$ are achieved in $>90 \%$ of rabbit lungs (16). Lungs can be perfused in this manner for up to $60 \mathrm{~min}$.

Lung perfusion protocols. After surgery, lungs were perfused for 5 min to ensure integrity of the preparation, as measured by normal pressures and negligible weight gain. Ventilation and perfusion were then stopped and the lungs were covered with moist gauze sponges to prevent dessication. The preparation was thereafter allowed to equilibrate to room temperature $\left(25^{\circ} \mathrm{C}\right)$, a process usually requiring $30 \mathrm{~min}$. After a 3-h interval of ischemia (usually $4 \mathrm{~h}$ from the point of exsanguination of the animal), ventilation was reinstated, initially at a tidal volume of $14 \mathrm{ml} / \mathrm{kg}$ to open atelectatic lung, then at the original tidal volume of $7 \mathrm{ml} / \mathrm{kg}$. Perfusion was then reinstated at $10 \mathrm{ml} / \mathrm{min}$ with increments of $5 \mathrm{ml} / \mathrm{min}$ every $15 \mathrm{~s}$ until the original flow of $50 \mathrm{ml} / \mathrm{min}$ was achieved. Perfusion was continued for $10 \mathrm{~min}$ to determine the effect of reventilation and reperfusion on pulmonary artery and tracheal pressures, and on lung weight gain from edema formation.

In selected experiments, the interval of ischemia was shortened from 3 to $2.5 \mathrm{~h}$ in an effort to decrease the severity of reperfusion injury and lengthen the time that reperfused lungs could be studied.

Pharmacologic interventions. Control lungs were perfused without treatment. Additional groups of lungs were perfused with one of the following interventional additions to the perfusate: the cyclooxygenase inhibitor of arachidonate metabolism indomethacin (16); the xanthine oxidase inhibitor allopurinol $(1,2)$; the antioxidant enzymes SOD and catalase (CAT) $(1,4)$; the iron chelator deferoxamine (17); and the thiols DMTU (18) or $N$-acetylcysteine (19). Allopurinol and DMTU were added to perfusate before surgical preparation so that blood was washed from the lung with buffer containing these agents. SOD and catalase were injected into the pulmonary artery just before reventilation and reperfusion. The remaining agents were added to the perfusate reservoir at the beginning of the baseline perfusion period.

Controls to enhance specificity of the pharmacologic probes included perfusing groups of lungs in which inactivated SOD, inactivated catalase, iron-saturated deferoxamine, or derivatized DMTU were added to the perfusate. SOD was inactivated by incubation with DDC to chelate the enzyme's copper, followed by dialysis against normal saline to remove the DDC-copper complex before use (20). Cata- lase was inactivated by boiling. Deferoxamine was iron saturated by incubation in $10 \mathrm{ml} 0.9 \% \mathrm{NaCl}$ with $\mathrm{FeCl}_{3}\left(8.5\right.$ parts by weight of $\mathrm{Fe}^{3+}$ to 100 parts of deferoxamine). DMTU was derivatized by incubation with slightly less than a half-molar equivalent of the alkylating agent $\mathrm{NEM}$ in $10 \mathrm{ml} 0.9 \% \mathrm{NaCl}$ for $30 \mathrm{~min}$ with gentle agitation. Unreacted NEM was removed by passing the mixture over a Sep-Pak column (C-18; Waters Associates Millipore Corp., Milford, MA) before adding inactivated DMTU to lung perfusate.

Measurement of in vivo superoxide production in ventilated and perfused lungs. In vivo $\mathrm{O}_{\overline{2}}^{\bar{z}}$ production by ventilated and perfused lung was measured by two techniques. The first technique assessed intracellular $\mathrm{O}_{\overline{2}}$ by a modification of the method of Kontos for measuring cerebral $\mathrm{O}_{\overline{2}}$ production (21). Detection of $\mathrm{O}_{\overline{2}}$ by this method relies on reduction of NBT to form insoluble formazan. Lungs were perfused with $300 \mu \mathrm{M}$ NBT added to the reservoir at the beginning of baseline perfusion for measurement of $\mathrm{O}_{\overline{2}}^{\overline{2}}$ production in reperfused lungs. As NBT was reduced, the lungs became tinted a deep purple. After $10 \mathrm{~min}$ of perfusion, lungs were quickly dissected free from the thorax. Wet and dry weight were obtained for one lung before and after drying for $72 \mathrm{~h}$ at $60^{\circ} \mathrm{C}$ for determination of wet/dry weight ratio. A $0.5-\mathrm{g}$ sample of the remaining lung was homogenized in cold $\left(4^{\circ} \mathrm{C}\right)$ normal saline, and centrifuged in the cold at $10,000 \mathrm{~g}$ for $10 \mathrm{~min}$. The pellet was resuspended in $5 \mathrm{ml}$ of reagent grade pyridine and placed in a heating block (Lab-Line Instruments, Melrose Park, IL) at $85^{\circ} \mathrm{C}$ for $4 \mathrm{~h}$ to extract formazan. The tube was then centrifuged at $10,000 \mathrm{~g}$ for $10 \mathrm{~min}$ and the supernatant containing pyridine was removed and evaporated under nitrogen. The residue containing the reduced NBT was redissolved in $2 \mathrm{ml}$ pyridine. Absorbance of $1 \mathrm{ml}$ of the solution was measured at $550 \mathrm{~nm}$ with a spectrophotometer (Gilford Instrument Laboratories, Inc., Oberlin, $\mathrm{OH}$ ) and the amount of NBT reduced was determined based on an extinction coefficient of $1.5 \times 10^{4} \mathrm{M}^{-1} \cdot \mathrm{cm}^{-1}$ (22) and corrected for grams dry weight of lung/minute.

A second technique was used to measure $\mathrm{O}_{\overline{2}}$ release into lung perfusate by SOD-inhibitable reduction of succinylated ferricytochrome $c$. Succinylated ferricytochrome $c$ was used as an indicating scavenger instead of native ferricytochrome $c$ to decrease interference from competing reductase reactions in biological systems (23). Type VI horse heart ferricytochrome $c$ was partially succinylated by the method of Kuthan et al. (23). Finely grained succinic anhydride (15.9 $\mathrm{mmol})$ was added to a vigorously stirred cold $\left(4^{\circ} \mathrm{C}\right)$ solution of ferricytochrome $c(300 \mu \mathrm{mol})$ in $1,500 \mathrm{ml}$ of potassium phosphate buffer $(0.03 \mathrm{M})$ over $30 \mathrm{~min}$. The $\mathrm{pH}$ of the solution was kept at 7.6 by titration with $2 \mathrm{M}$ potassium hydroxide. The solution was stirred for an additional $20 \mathrm{~min}$, dialyzed against double-distilled deionized water for $24 \mathrm{~h}$, and lyophilized. Succinylated cytochrome $c$ was stored at $-70^{\circ} \mathrm{C}$ before use. The preparation had $38 \%$ of the trinitrobenzenesulfonic acid (TNBS) reactive amine groups of the cytochrome $c$ molecule (24).

$\mathrm{O}_{\overline{2}}^{\overline{2}}$ was measured in perfusate by adding $60 \mu \mathrm{M}$ succinylated ferricytochrome $c$ to the reservoir just before reventilation and reperfusion. After restoration of flow to $50 \mathrm{ml} / \mathrm{min}, 2-\mathrm{ml} \mathrm{samples} \mathrm{of} \mathrm{perfusate} \mathrm{were}$ withdrawn from the outflow cannula at timed intervals of $1,2.5,5,7.5$, and $10 \mathrm{~min}$ of perfusion. Samples were centrifuged at $1,000 \mathrm{~g}$ for 10 min to remove debris, and perfusate absorbance was determined at 550 $\mathrm{nm}$. The change in absorbance between each timed sample and that of $60 \mu \mathrm{M}$ succinylated ferricytochrome $c$ in unperfused buffer was used with an extinction coefficient of $2.1 \times 10^{4} \mathrm{M}^{-1} \cdot \mathrm{cm}^{-1}(23)$ to determine ferricytochrome $c$ reduction.

Experiments with anion channel blockade. To gain further insight into the origin of $\mathrm{O}_{\overline{2}}$ in reperfusion injury, lungs were perfused with the anion channel blocker DIDS $(100 \mu \mathrm{M})$ added to the reservoir during baseline perfusion. The exchange of monovalent anions through cell membranes is mediated by the large transmembrane protein known as band 3 protein (25). Charged $\mathrm{O}_{\bar{i}}$ radicals have been previously shown to pass freely through cell membranes via this anion channel (26). DIDS is a reversible specific blocker of the anion channel (27) and was given to prevent intracellular $\mathrm{O}_{\overline{2}}$ formed during reventilation and reperfusion from exiting into the extracellular medium. The DIDS- 
treated lungs were subsequently reperfused with active SOD, without SOD, or with $1.5 \mathrm{mM}$ allopurinol added to perfusate as described above. All DIDS-perfused lungs were studied in a darkened room to prevent photolytic decomposition of DIDS.

Statistical analysis. Values for pulmonary artery pressure $\left(P_{\mathrm{pa}}\right)$, maximal inspiratory tracheal pressure $\left(P_{\mathrm{T}}\right.$, as measured from functional residual capacity), cumulative lung weight gain, and ferricytochrome $c$ reduction among experimental groups were analyzed by two-way analysis of variance with randomized split-block design (28). Rates of lung weight gain $(\Delta W)$ and NBT reduction among experimental groups were analyzed by one-way analysis of variance (29). Comparisons among groups were performed with Duncan's multiple range test (30). Significance was assumed when $P<0.05$. Values are reported as mean \pm SEM.

\section{Results}

Characterization of the model. Fig. 1 shows a typical experiment in an untreated control lung. During $5 \mathrm{~min}$ of baseline perfusion, pulmonary artery and tracheal pressures remained normal, and there was negligible weight gain. After $3 \mathrm{~h}$ of ischemia, reventilation and reperfusion of untreated control lungs resulted in marked pulmonary edema, characterized by elevations in $P_{\mathrm{pa}}, P_{\mathrm{T}}$, and $\Delta \mathrm{W} . P_{\mathrm{pa}}$ rose to a maximum $\left(P_{\mathrm{pa} \mathrm{max}}\right.$ $=30 \pm 2 \mathrm{mmHg}, P<0.001$ compared with baseline) while flow was being increased back to $50 \mathrm{ml} / \mathrm{min}$. Thereafter, $P_{\mathrm{pa}}$ slowly fell, but remained elevated above baseline level. $P_{\mathrm{T}}$ and $\Delta \mathrm{W}$ also increased significantly during the $10 \mathrm{~min}$ of reperfusion $\left(P_{\mathrm{T}}=\right.$ to $24 \pm 4 \mathrm{mmHg}, \Delta \mathrm{W}$ to $3.62 \pm 0.76 \mathrm{~g} / \mathrm{min}, P<0.001$ compared with baseline). By the end of reperfusion, this preparation and all other untreated control lungs were obviously edematous, with frothy fluid filling the tracheal cannula. The rise in $P_{\mathrm{pa}}$ during reperfusion was prevented by adding $5 \mu \mathrm{g} / \mathrm{ml}$ of the cyclooxygenase inhibitor indomethacin to the perfusate (Fig. 2). However, indomethacin did not prevent the increase in $P_{\mathrm{T}}(17 \pm 3.5 \mathrm{mmHg})$ and $\Delta \mathrm{W}(3.20 \pm 1.50 \mathrm{~g} / \mathrm{min})$, or the development of pulmonary edema during reperfusion. This suggests that edema formation during reventilation and reperfusion is due not only to a rise in perfusion pressure, but is also

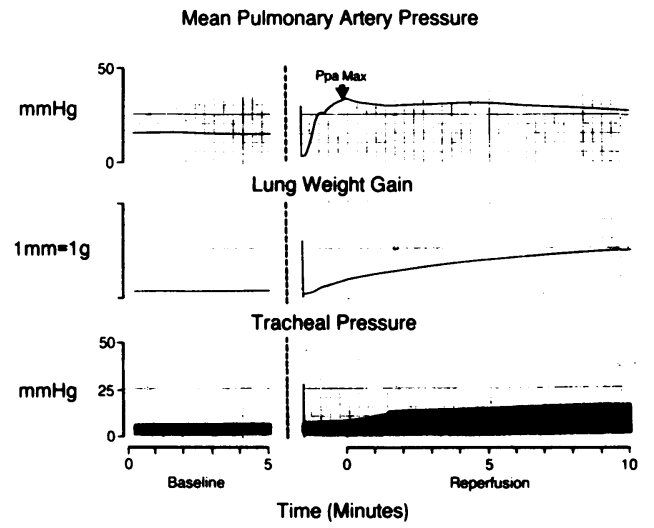

Figure 1. Typical reperfusion experiment after $3 \mathrm{~h}$ of ischemia. During baseline, pulmonary artery and tracheal pressures are normal and rate of lung weight gain is negligible. Resumption of ventilation and perfusion after $3 \mathrm{~h}$ of ischemia results in an elevation in pulmonary artery pressure to a maximum $\left(P_{\mathrm{pa} \max }\right)$ while flow is being gradually increased to the normal level of $50 \mathrm{ml} / \mathrm{min}$. Pulmonary artery pressure then slowly decreases but remains substantially elevated above baseline. Tracheal pressure and rate of lung weight gain increase progressively, resulting in pulmonary edema after $<10 \mathrm{~min}$ of reperfusion.

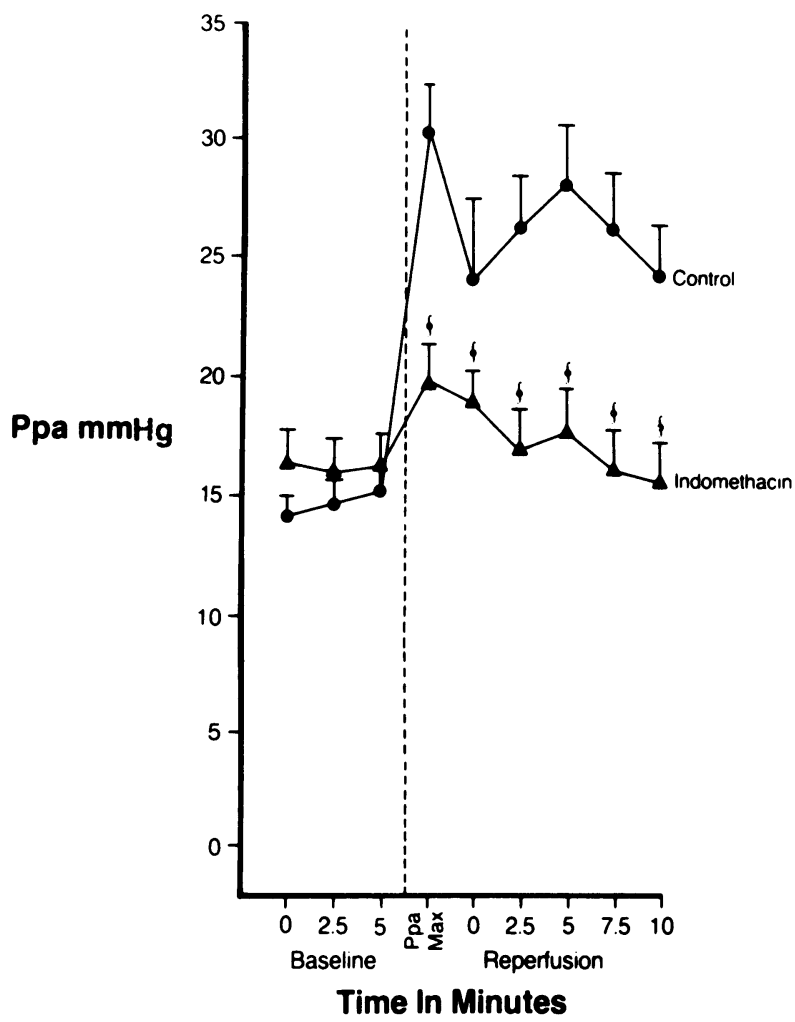

Figure 2. Indomethacin prevents vasoconstriction during reperfusion of ischemic lungs. Reperfusion and reventilation of untreated control lungs after $3 \mathrm{~h}$ of ischemia results in an elevation in pulmonary artery pressure $\left(P_{\mathrm{pa}}\right)$ from vasoconstriction in untreated control lungs $(n=10)$. Lungs treated with the cyclooxygenase inhibitor indomethacin $(5 \mu \mathrm{g} / \mathrm{ml}, n=5)$ do not experience a rise in $P_{\mathrm{pa}}$. This suggests that pulmonary vasoconstriction is due to a cyclooxygenase metabolite of AA. ${ }^{\S} P<0.001$ compared with untreated control lungs.

a result of injury to pulmonary microvasculature. Results with indomethacin treated lungs also indicate that the rise in $P_{\mathrm{pa}}$ during reperfusion is from pulmonary vasoconstriction caused by cyclooxygenase metabolites of AA $(16,31)$.

When the duration of ischemia was shortened to $2.5 \mathrm{~h}$ to lengthen the time lungs could be studied, untreated reperfused lungs (Table I) did not experience the profound rise in $P_{\mathrm{pa}}$ that had been observed in the $3-\mathrm{h}$ ischemia group. Nonetheless, untreated reperfused lungs in these experiments gained more weight than normal nonreperfused lungs $(1.52 \pm 0.36 \mathrm{~g} / \mathrm{min}$ compared with $0.11 \pm 0.02 \mathrm{~g} / \mathrm{min}$ in nonreperfused lungs, $P<0.05)$.

Effects of antioxidant interventions. In view of the central role of xanthine oxidase as the enzymatic origin of reactive oxygen species in reperfusion injury of other organs $(1,2)$, we critically evaluated the effects of an inhibitor of xanthine oxidase on lung injury in our model. Fig. 3 shows that pretreatment of lungs with the xanthine oxidase inhibitor allopurinol (1.5 $\mathrm{mM})$, prevents lung injury after reventilation and reperfusion. $P_{\mathrm{pa}}, P_{\mathrm{T}}$, and $\Delta \mathrm{W}$ from treated groups were all significantly lower than in untreated controls. Because allopurinol has been demonstrated to show scavenging activity for $\cdot \mathrm{OH}$ (32), we also performed experiments with lower concentrations $(100 \mu \mathrm{M})$ to enhance specificity of the probe for inhibiting xanthine oxidase. This lower concentration also prevented lung injury after reventilation and reperfusion (Fig. 3). 
Table I. Effect of Catalase on Reperfusion Lung Injury

\begin{tabular}{|c|c|c|c|c|c|c|c|c|c|c|}
\hline \multirow[b]{2}{*}{ Time $(\min )$} & \multicolumn{2}{|c|}{ Baseline } & \multirow[b]{2}{*}{$P_{\text {pe } \max }$} & \multicolumn{7}{|c|}{ Reperfusion } \\
\hline & 0 & 5 & & 0 & 5 & 10 & 15 & 20 & 25 & 30 \\
\hline \multicolumn{11}{|l|}{$P_{\mathrm{pa}}(m m H g)$} \\
\hline Nonreperfused & $10 \pm .5$ & $10 \pm .5$ & $10 \pm .5$ & $10 \pm .5$ & $10 \pm .4$ & $12 \pm .6$ & $13 \pm 1$ & $14 \pm 2$ & $14 \pm 2$ & $14 \pm 2$ \\
\hline Reperfused & $11 \pm .7$ & $11 \pm .5$ & $18 \pm .8^{*}$ & $17 \pm .5$ & $14 \pm 1$ & $13 \pm 1$ & $13 \pm 1$ & $12 \pm 1$ & $12 \pm 1$ & $12 \pm 1$ \\
\hline Reperfused + CAT & $15 \pm 5^{*}$ & $15 \pm .4^{*}$ & $17 \pm .7^{*}$ & $17 \pm .7$ & $17 \pm .7^{\ddagger}$ & $16 \pm .4^{\ddagger}$ & $15 \pm .5^{\ddagger}$ & $14 \pm .6$ & $14 \pm .7$ & $13 \pm .8$ \\
\hline \multicolumn{11}{|l|}{$P_{\mathrm{T}}(m m H g)$} \\
\hline Nonreperfused & $7 \pm .6$ & $7 \pm .6$ & & $8 \pm .7$ & $8 \pm .8$ & $8 \pm .8$ & $8 \pm .9$ & $9 \pm 1$ & $9 \pm 1$ & $9 \pm 1$ \\
\hline Reperfused & $7 \pm .5$ & $7 \pm .6$ & & $12 \pm 2 *$ & $13 \pm 1^{*}$ & $15 \pm 1^{*}$ & $16 \pm 1^{*}$ & $16 \pm 1$ & $16 \pm 1$ & $15 \pm 2$ \\
\hline Reperfused + CAT & $8 \pm .3$ & $8 \pm .3$ & & $10 \pm .4^{\ddagger}$ & $12 \pm .4$ & $13 \pm .4^{\ddagger}$ & $13 \pm .6^{\ddagger}$ & $13 \pm .6$ & $14 \pm .6$ & $14 \pm .6$ \\
\hline
\end{tabular}

${ }^{*} P<0.05,{ }^{\ddagger} P<0.01$ compared with control. Values are mean \pm SEM. $P_{\mathrm{pa}}$, pulmonary artery pressure; $P_{\mathrm{T}}$, tracheal pressure; nonreperfused, five lungs perfused for 35 min beginning at time 0 in the baseline period; reperfused, five reperfused lungs; reperfused + CAT, five lungs reperfused after catalase 50,000 U was injected into the pulmonary artery just before reventilation; Because only three of five untreated lungs could be perfused longer than $15 \mathrm{~min}$, analysis was stopped after $15 \mathrm{~min}$ of reperfusion.

Support for oxidant-mediated injury in this model was provided by pretreatment with the antioxidant enzymes SOD $(25,000 \mathrm{U})$ or CAT $(50,000 \mathrm{U})$. Results of pretreatment of lungs with SOD just before reventilation and reperfusion are shown in Fig. 4. Active SOD prevented lung injury, as measured by $P_{\mathrm{pa}}$ and $\Delta \mathrm{W}$. The values for $P_{\mathrm{T}}$ were lower in SODtreated lungs at a level of significance of $P=0.06$. Inactivated SOD failed to prevent lung edema, as measured $\Delta \mathrm{W}$ and $P_{\mathrm{T}}$. $P_{\mathrm{pa}}$ was lower, however, in lungs treated with inactivated SOD than in untreated control lungs. The reason for differences in $P_{\mathrm{pa}}$ between the inactive SOD-treated group and control reperfused lungs is not apparent at this time and will require further investigation. The effect of catalase on reperfusion lung injury was studied using a $2.5-\mathrm{h}$ period of ischemia. Catalase provided significant protection from reperfusion injury, with a cumulative lung weight gain that was one-third that of untreated reperfused lungs (Fig. 5). $P_{\mathrm{T}}$ was also significantly lower in CAT-treated lungs (Table I). All catalase treated lungs were successfully reperfused for a full $30 \mathrm{~min}$, whereas some of the untreated ischemic lungs could not be reperfused that long because of extensive edema formation, with cumulative weight gains of almost $50 \mathrm{~g}$. Inactivated catalase failed to protect two lungs from reperfusion injury (cumulative lung weight gains of 18 and $25 \mathrm{~g}$, respectively, over $30 \mathrm{~min}$ ). To our surprise, $P_{\mathrm{pa}}$ was significantly higher in catalase treated reperfused lungs (Table I) than in either nonreperfused or untreated reperfused lungs. The reason for this observation is presently not clear.

The protective effects of either SOD or catalase suggested that an $\mathrm{O}_{\overline{2}}$-driven Fenton reaction may be responsible for lung injury in this model. Fig. 6 shows that pretreatment of lungs with the iron chelator deferoxamine $(10 \mathrm{mM})$, or the thiols DMTU (45 mM) or $N$-acetylcysteine $(5 \mathrm{mM})$, prevents lung injury after reventilation and reperfusion. $P_{\mathrm{pa}}, P_{\mathrm{T}}$, and $\Delta \mathrm{W}$ from treated groups were all significantly lower than in untreated controls. Because deferoxamine (33) has been demonstrated to show scavenging activity for $\cdot \mathrm{OH}$, we also performed experiments with lower concentrations of this agent $(100 \mu \mathrm{M})$ to enhance its specificity as a probe for chelating iron. This lower concentration of deferoxamine also prevented lung injury after reperfusion and reventilation $(\Delta \mathrm{W}$ $=0.24 \pm 0.10 \mathrm{~g} / \mathrm{min}$ for five lungs, $P<0.001$ compared with untreated reperfused lungs). Iron-saturated deferoxamine (10 $\mathrm{mM})$ did not protect from reperfusion injury $(\Delta \mathrm{W}=0 \mathrm{~g} / \mathrm{min}$ during baseline; $3.83 \pm 1.31 \mathrm{~g} / \mathrm{min}$ during reperfusion). Lungs reperfused with derivatized DMTU ( $45 \mathrm{mM}$ ) gained no weight during baseline $(\Delta \mathrm{W}=0 \mathrm{~g} / \mathrm{min})$ but developed edema $(\Delta \mathrm{W}$ $=30.5 \pm 0.50 \mathrm{~g} / \mathrm{min}$ ) during reperfusion that was significantly worse than in untreated reperfused lungs $(P<0.05)$.

In vivo measurements of $O_{\overline{2}}^{-}$release. To better characterize the role of reactive oxygen species in reperfusion lung injury, we measured in vivo lung $\mathrm{O}_{\bar{z}}$ generation by reduction of NBT or succinylated ferricytochrome $c$. As shown in Fig. 7, nonreperfused lungs reduced $61 \pm 12 \mu \mathrm{mol} \mathrm{NBT} / \mathrm{g}$ dry lung per min. The NBT reduction that occurred during baseline was not inhibited by SOD and is probably best explained by the ability of metabolizing cells to also reduce NBT by NADH and NADPH reductases, so that only a portion of NBT is reduced by $\mathrm{O}_{\bar{i}} \overline{-}$-dependent mechanisms (22). During reperfusion, reduction rose more than threefold to $208 \pm 35 \mu \mathrm{mol} \mathrm{NBT} / \mathrm{g}$ dry lung per $\min (P<0.001$ compared with nonreperfused lungs). When SOD was injected into the pulmonary artery prior to reventilation and reperfusion, the rise in NBT reduction that occurred during reperfusion was blocked $(64 \pm 3 \mu \mathrm{mol} \mathrm{NBT} / \mathrm{g}$ dry lung per min, $P<0.05$ compared with untreated reperfused lungs, but not significantly different from nonreperfused lungs). Allopurinol (1.5 mM) also decreased NBT reduction compared with that in untreated reperfused lungs (124 \pm 16 $\mu \mathrm{mol}$ NBT reduced/g dry lung per min, $P<0.05$ ), but reduction was still twice that of nonreperfused controls.

Fig. 8 shows results of in vivo $\mathrm{O}_{\bar{z}}$ generation measured by reduction of succinylated ferricytochrome $c$ in perfusate over $10 \mathrm{~min}$. Reduction occurred in uninjured nonreperfused lungs, but did not increase substantially over time and was inhibited only slightly by SOD. In contrast, reduction of succinylated ferricytochrome $c$ was significantly higher in reperfused lungs $(P<0.001$ compared with uninjured nonreperfused lungs), increased over the course of $10 \mathrm{~min}(0.41 \pm 0.05$ $\mu \mathrm{M} / \mathrm{min})$, and was significantly inhibited by SOD back to levels of reduction observed in uninjured control lungs $(P$ $<0.001$ for SOD reperfused lungs compared with lungs reperfused without SOD). ${ }^{2}$ This constitutes evidence for increased

2. Perfusate from reperfused ischemic lungs had an increase in $A_{550}$ of $0.265 \pm 0.019$ over $10 \mathrm{~min}$, compared with increases of $0.130 \pm 0.006$ in nonreperfused normal lungs, $0.113 \pm 0.008$ in nonreperfused lungs treated with SOD, and $0.139 \pm 0.029$ in reperfused lungs treated with SOD. 


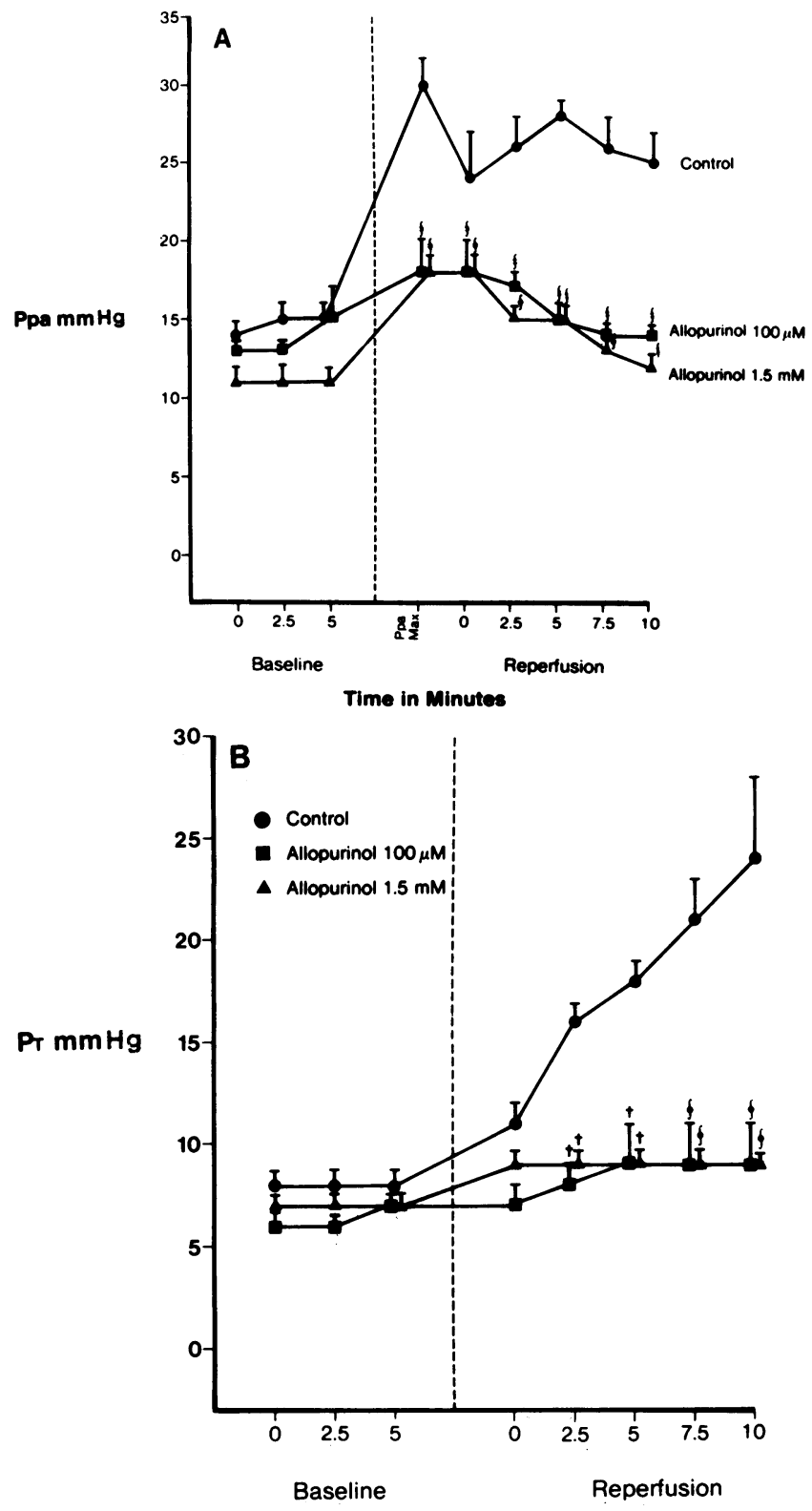

Time in Minutes

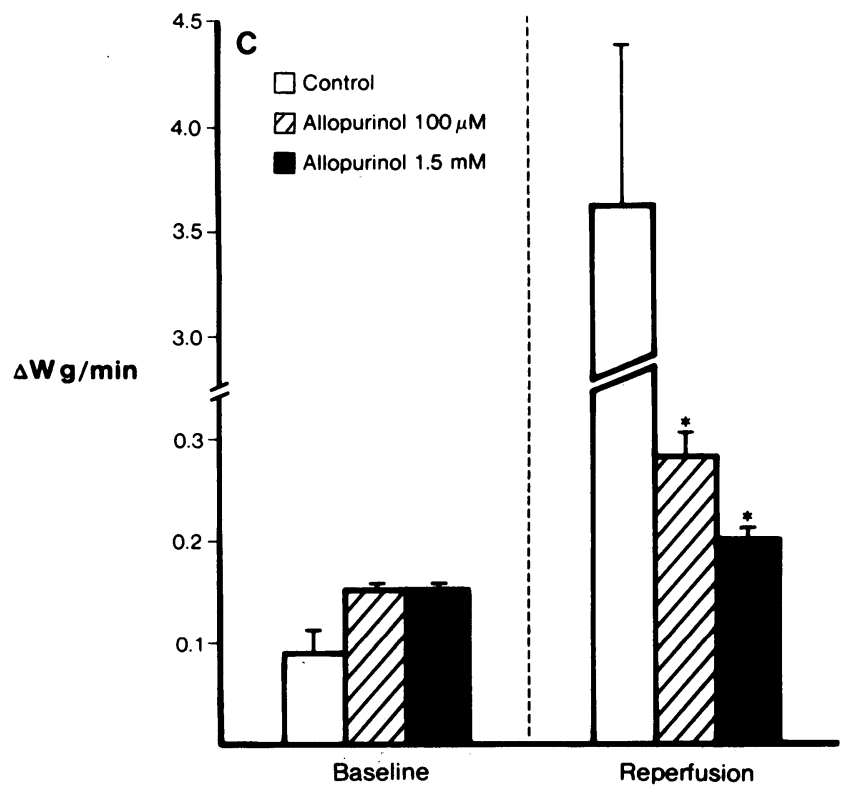

$\mathrm{O}_{\overline{2}}^{\overline{2}}$ release into lung perfusate during reperfusion. Succinylated ferricytochrome $c$ alone did not protect from reperfusion injury $(\Delta \mathrm{W}=0.05 \pm 0.02 \mathrm{~g} / \mathrm{min}$ during baseline; $2.08 \pm 0.32$ $\mathrm{g} /$ min during reperfusion), whereas lungs perfused with ferricytochrome $c+$ SOD were protected $(\Delta \mathrm{W}=0.08 \pm 0.03 \mathrm{~g} / \mathrm{min}$ during baseline; $0.38 \pm 0.13 \mathrm{~g} / \mathrm{min}$ during reperfusion, $P<0.05$ compared with lungs perfused with cytochrome $c$ alone).

Fig. 8 also shows the effect of DIDS $(100 \mu \mathrm{M})$ allopurinol (1.5 mM), deferoxamine (10 $\mathrm{mM})$, and DMTU (45 $\mathrm{mM})$ on succinylated ferricytochrome $c$ reduction during reperfusion. DIDS decreased reduction of cytochrome $c$ to levels lower than in nonreperfused lungs. This suggests that $\mathrm{O}_{\overline{2}}^{-}$is generated within the cell and enters the perfusate by transport across anion channels of cell membranes. Allopurinol decreased cytochrome $c$ reduction during reperfusion, but the level of reduction was still higher than in nonreperfused lungs or lungs reperfused with SOD. Cytochrome $c$ reduction was higher in lungs treated with deferoxamine than in untreated reperfused lungs. Cytochrome $c$ reduction in DMTU-treated lungs was lower than in untreated reperfused lungs, but still higher than in uninjured lungs not reperfused or lungs reperfused with SOD.

Effects of anion channel blockade. The effect of anion channel blockade with DIDS on reperfusion lung injury is shown in Table II. The protective effect of SOD on reperfusion lung injury is eliminated by anion channel blockade of lung cells with DIDS. In contrast, DIDS does not prevent allopurinol, an intracellular inhibitor of the generation of $\mathrm{O}_{\overline{2}}^{\overline{2}}$ by xanthine oxidase, from protecting against reperfusion injury.

\section{Discussion}

In our study, we have found that restoration of ventilation and perfusion to ischemic lungs results in pulmonary vasoconstriction and microvascular injury. The pulmonary vasoconstriction is likely due to generation of cyclooxygenase products from AA, because increases in $P_{\mathrm{pa}}$ are prevented by the cyclooxygenase inhibitor indomethacin. Cyclooxygenase metabolites, specifically thromboxane, have been shown to mediate vasoconstriction in other models of oxidant lung injury in the rabbit $(16,31)$. However, additional studies, including measurement of arachidonate products released during reperfusion, will be needed to clarify the role of arachidonate mediators in promoting reperfusion lung injury.

We have established that oxidant injury is the cause of pulmonary edema after reventilation and reperfusion by directly measuring enhanced $\mathrm{O}_{\overline{2}}^{\bar{z}}$ generation in reperfused lung and by blocking reperfusion injury with accepted inhibitors of free radical-mediated reperfusion injury in other organs. Prevention of injury by pretreatment of lungs with SOD or catalase indicates that $\mathrm{O}_{\overline{2}}$ and $\mathrm{H}_{2} \mathrm{O}_{2}$ are important in initiating injury. Blockade of injury with the iron chelator deferoxamine suggests that an iron-mediated Fenton reaction is necessary for toxicity to occur. While it is possible that deferoxamine was

Figure 3. Allopurinol prevents reperfusion lung injury. The xanthine oxidase inhibitor allopurinol $(1.5 \mathrm{mM} ; n=5)$ or $(100 \mu \mathrm{M} ; n=5)$ prevents the increase in pulmonary artery pressure $\left(P_{\mathrm{pa}}, A\right)$, tracheal pressure $\left(\mathrm{P}_{\mathrm{T}}, B\right)$, and rate of lung weight gain $(\Delta \mathrm{W}, C)$ during reperfusion and reventilation after $3 \mathrm{~h}$ of ischemia, compared with control lungs $(n=10) .{ }^{*} P<0.05,{ }^{\dagger} P<0.01,{ }^{\S} P<0.001$ compared with untreated control lungs. 

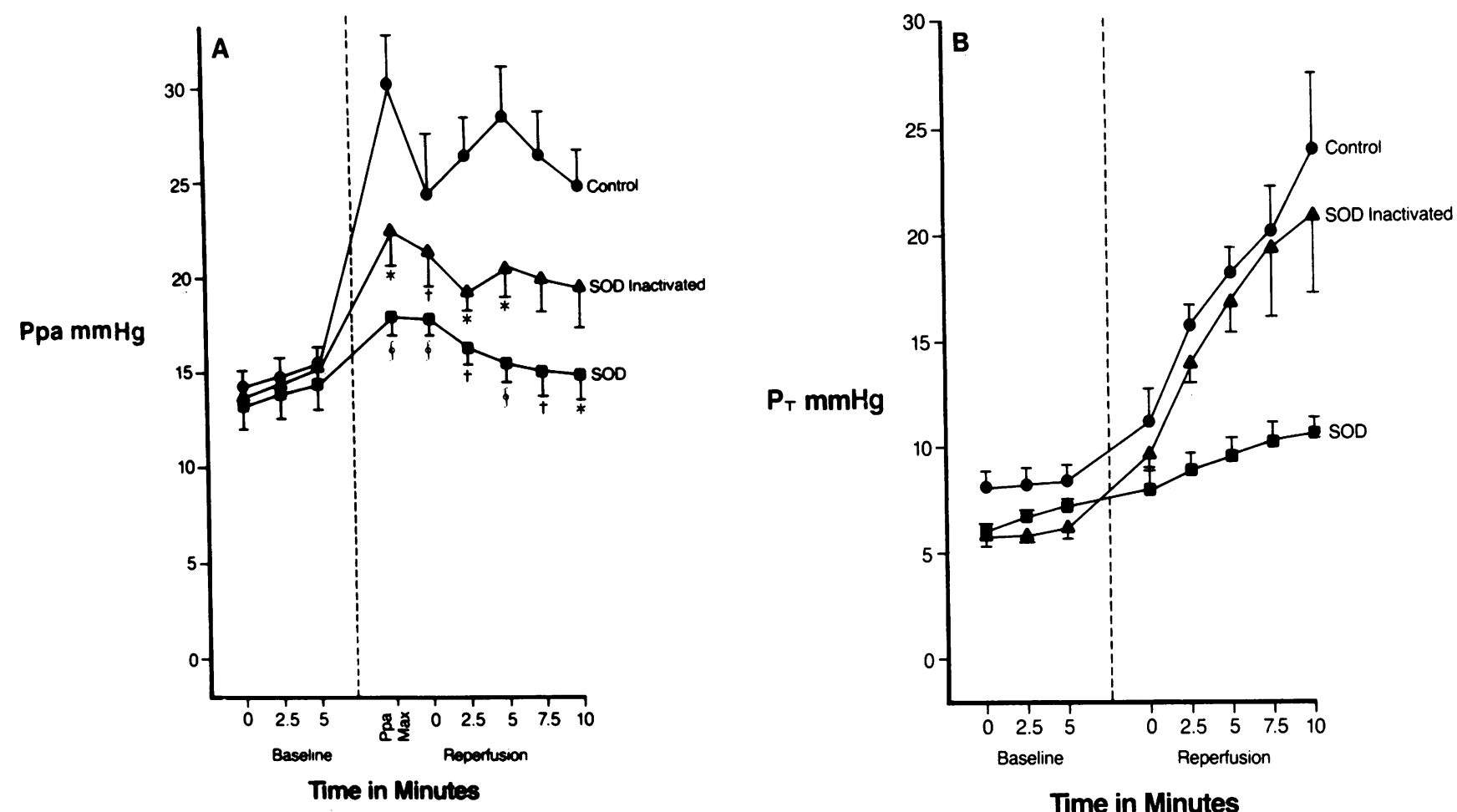

Time in Minutes
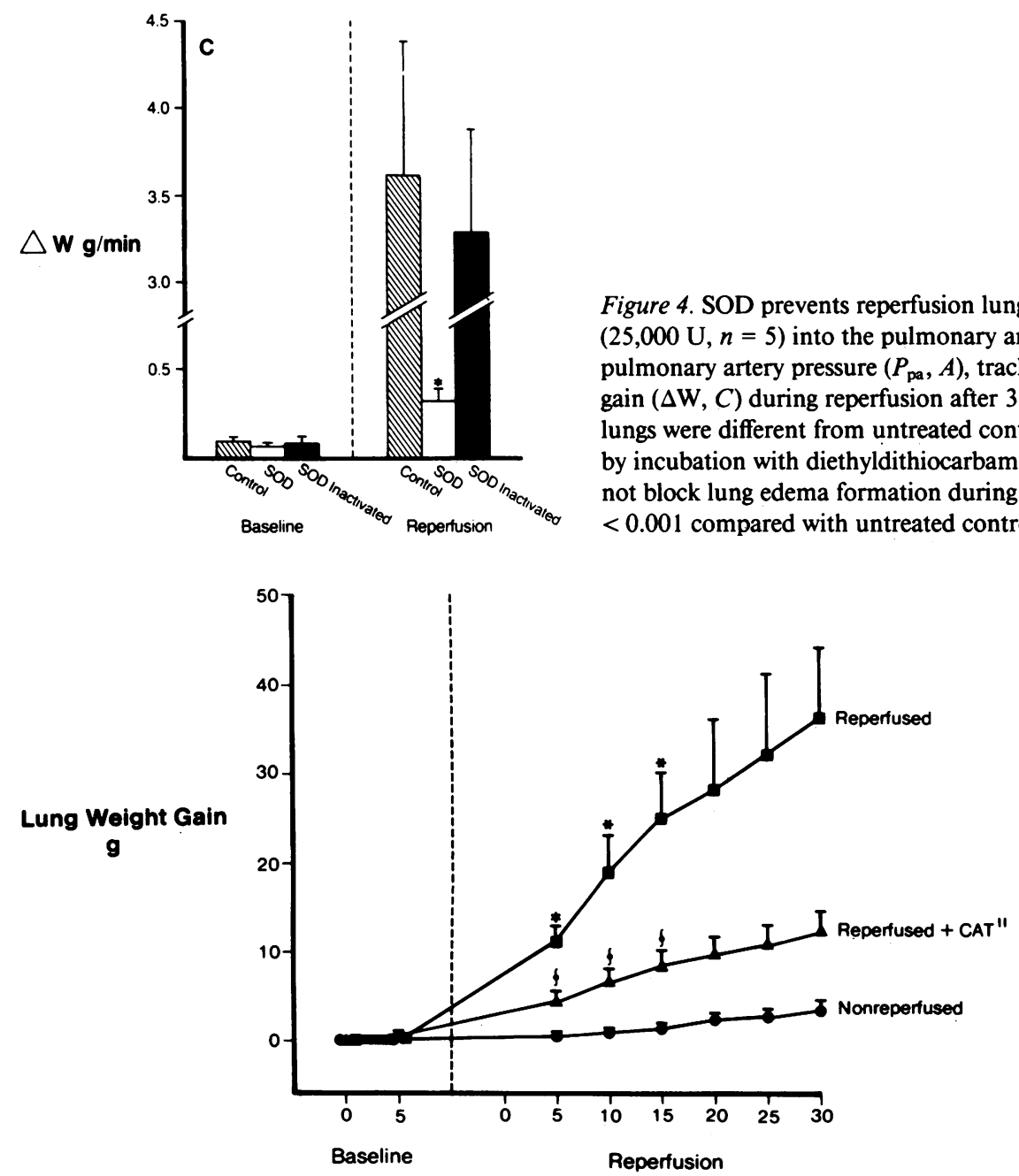

Time in Minutes
Figure 4. SOD prevents reperfusion lung injury. Injection of the $\mathrm{O}_{\bar{z}}$ scavenger SOD $(25,000 \mathrm{U}, n=5)$ into the pulmonary artery just before reventilation prevents the rise in pulmonary artery pressure $\left(P_{\mathrm{pa}}, A\right)$, tracheal pressure $\left(\mathrm{P}_{\mathrm{T}}, B\right)$, and rate of lung weight gain $(\Delta \mathrm{W}, C)$ during reperfusion after $3 \mathrm{~h}$ of ischemia. Values for $P_{\mathrm{T}}$ in SOD-treated lungs were different from untreated control lungs $(n=10)$ at $P=0.06$. SOD inactivated by incubation with diethyldithiocarbamate to chelate the enzyme's copper $(n=5)$ did not block lung edema formation during reperfusion $(C) .{ }^{*} P<0.05,{ }^{\dagger} P<0.01,{ }^{\S} P$ $<0.001$ compared with untreated control lungs.
Figure 5. Catalase prevents reperfusion lung injury. Untreated lungs reperfused $(n=5)$ after $2.5 \mathrm{~h}$ of ischemia still developed profound injury compared with nonreperfused normal lungs ( $n=5$ ), with marked increase in cumulative lung weight gain over $30 \mathrm{~min}$ of perfusion. Reperfusion injury was significantly attenuated by injection of 50,000 $\mathrm{U}$ of the $\mathrm{H}_{2} \mathrm{O}_{2}$ scavenger catalase (Reperfused + CAT, $n=5$ ) in the pulmonary artery just before reventilation." Because only three of five untreated lungs could be reperfused for $>15$ minutes, analysis was performed only up to this time. ${ }^{*} P<0.001$ compared with nonreperfused lungs. ${ }^{\S} P<0.001$ compared with reperfused lungs. 

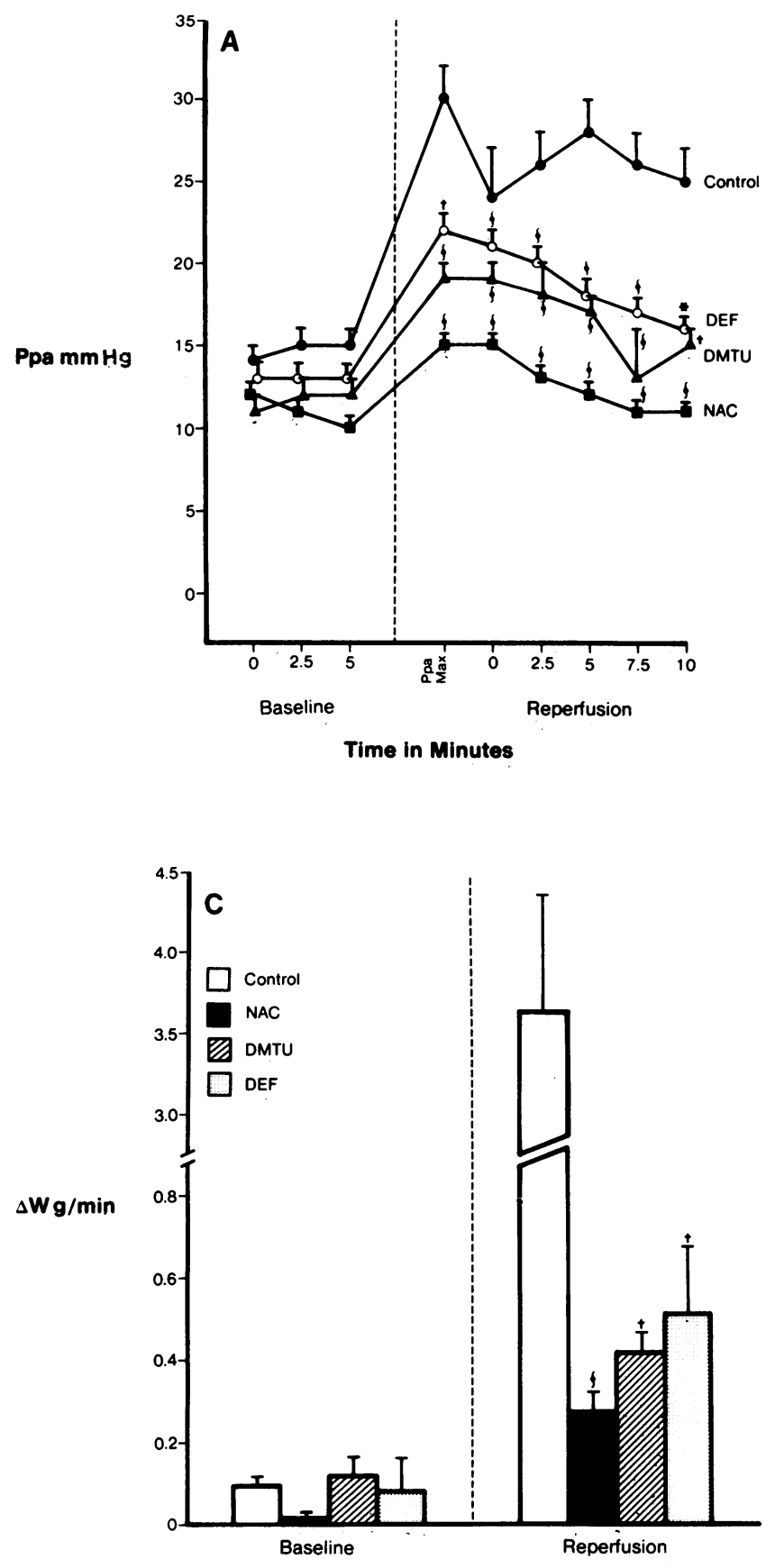

effective in part as a $\cdot \mathrm{OH}$ scavenger (33), the failure of ironsaturated deferoxamine to protect against injury points to a pivotal role of iron in reperfusion injury. Intracellular iron is normally bound as cofactor to enzymes or stored within the protein ferritin. However, there is a rapid release of iron from ferritin under ischemic conditions (34). It has also been shown recently that $\mathrm{O}_{\overline{2}}^{-}$can directly mediate reductive release of iron from ferritin (35). Free iron could, in turn, promote generation of $\cdot \mathrm{OH}$ from $\mathrm{H}_{2} \mathrm{O}_{2}$ by the Fenton reaction. Whereas the Fenton mechanism is supported in our studies by the effectiveness of DMTU (18) or $N$-acetylcysteine (19) in preventing reperfusion injury, these thiol compounds might have provided protection by means other than scavenging $\cdot \mathrm{OH}$.

Using two different detector molecules, we have demonstrated evidence for enhanced $\mathrm{O}_{\overline{2}}^{\bar{z}}$ generation during reperfu-

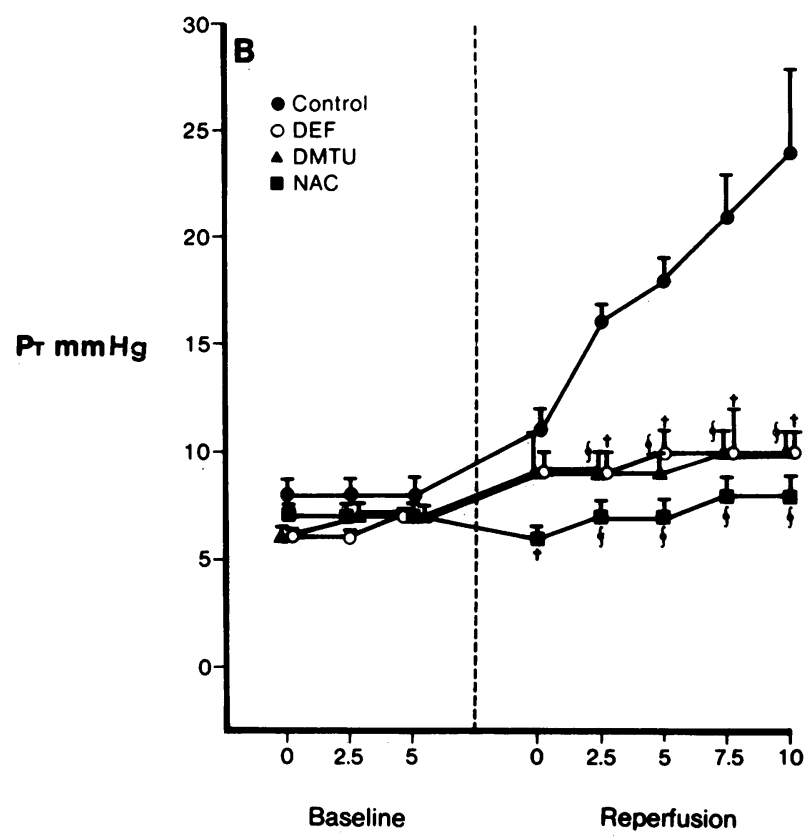

Time in Minutes

Figure 6. Deferoxamine and thiols prevent reperfusion lung injury. Perfusion of lungs with the iron chelator deferoxamine $(10 \mathrm{mM})$ (DEF, $n=5)$, or the thiols DMTU $(45 \mathrm{mM})(n=5)$ or $N$-acetylcysteine $(5 \mathrm{mM})(\mathrm{NAC}, n=5)$ prevents elevation of pulmonary artery pressure $\left(P_{\mathrm{pa}}, A\right)$, tracheal pressure $\left(P_{\mathrm{T}}, B\right)$ and rate of lung weight gain $(\Delta \mathrm{W}, C)$ during reperfusion after $3 \mathrm{~h}$ of ischemia, compared with untreated control lungs $(n=10) .{ }^{*} P<0.05,{ }^{\dagger} P<0.01,{ }^{8} P$ $<0.001$ compared with untreated control lungs.

sion of ischemic lung. These detector molecules are complementary but have notable differences. Ferricytochrome $c$ is a large $(12,384 \mathrm{~mol} \mathrm{wt})$ molecule that detects only $\mathrm{O}_{\overline{2}}$ released into the extracellular space, whereas NBT can be reduced intracellularly by metabolically active cells $(21,22)$. Also, whereas both NBT (22) and ferricytochrome $c$ (23) can be acted on by a number of competing reductase reactions, ferricytochrome $c$ is much more specific for $\mathrm{O}_{\overline{2}}$ (23) than is NBT (22). Thus, we favor succinylated ferricytochrome $c$ as a detector molecule for $\mathrm{O}_{\overline{2}}$ in our model, even though it is less sensitive than NBT.

Despite the fact that they probably reflect events in different compartments, measurement of NBT (Fig. 7) and succinylated ferricytochrome $c$ (Fig. 8) reduction provide insight into the sources of $\mathrm{O}_{\overline{2}}^{-}$generation during reperfusion. First, 


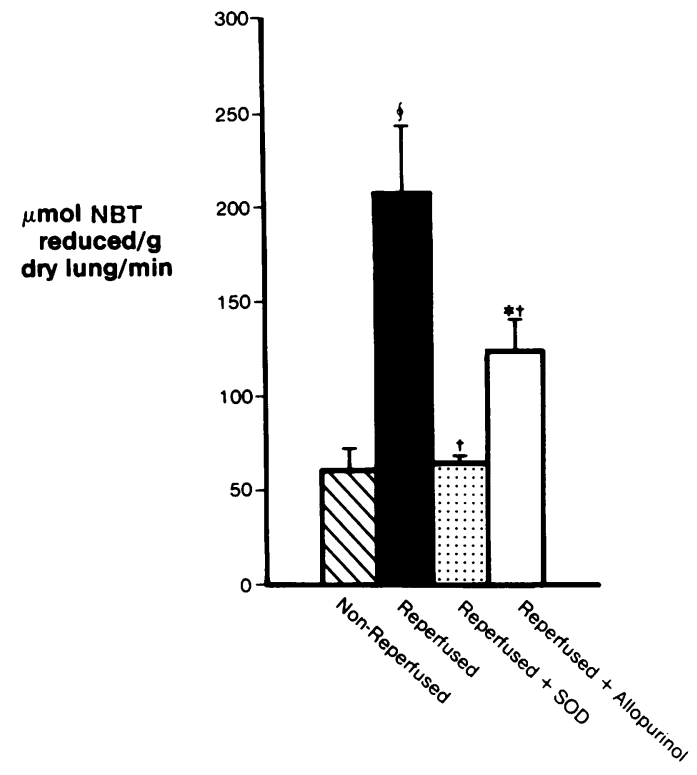

Figure 7. Reperfusion $\mathrm{O}_{\overline{2}}^{\overline{2}}$ generation measured by NBT reduction. Reduction of the intracellular and extracellular $\mathrm{O}_{\overline{2}}$ detector NBT over $10 \mathrm{~min}$ of perfusion ( $\mu \mathrm{mol} \mathrm{NBT}$ reduced/g dry lung/min) is significantly increased in lungs reperfused after $3 \mathrm{~h}$ of ischemia, compared with normal nonreperfused lungs. Injection of 25,000 U SOD into the pulmonary artery just before reventilation and reperfusion completely blocks the reperfusion-related increase in NBT reduction. Allopurinol ( $1.5 \mathrm{mM})$ also significantly decreases NBT reduction during reperfusion, but does not reduce reduction to background levels seen in nonreperfused lungs. $n=4$ in each group. ${ }^{*} P<0.05$, ${ }^{\$} P<0.001$ compared with nonreperfused lungs. ${ }^{\dagger} P<0.05$ compared with reperfused lungs.

both NBT and cytochrome $c$ reduction during reperfusion were decreased by SOD to levels seen in nonreperfused lung, indicating that reduction of detectors was from $\mathrm{O}_{\bar{z}}$ generation $(22,36)$. Second, deferoxamine and DMTU protected from reperfusion lung injury (Fig. 6) but did not prevent ferricytochrome $c$ reduction during reperfusion. Thus, decreased detector molecule reduction in lungs treated with SOD did not occur simply because SOD attenuated reperfusion injury, since reduction of cytochrome $c$ was even higher in deferoxamine-treated reperfused lungs than in untreated reperfused lungs (Fig. 8). Finally, results in Figs. 7 and 8 indicate that $\mathrm{O}_{\overline{\dot{2}}}$ generated during reperfusion comes from intracellular sources, because anion channel blockade prevented reduction of the extracellular detector succinylated ferricytochrome $c$. The decrease in both NBT and cytochrome $c$ reduction by allopurinol is consistent with the hypothesis that xanthine oxidase is an important intracellular source of $\mathrm{O}_{\overline{2}}$ produced during reperfusion injury $(1,2,8,10,11)$.

Allopurinol provided significant protection against reperfusion lung injury in our model (Fig. 3). However, it did not completely suppress enhanced NBT or cytochrome $c$ reduction during reperfusion. Thus, allopurinol may protect in ways additive to inhibition of xanthine oxidase, such as functioning as a $\cdot \mathrm{OH}$ scavenger (32). The failure of allopurinol to completely suppress NBT and cytochrome $c$ reduction may also indicate that sources other than xanthine oxidase exist for $\mathrm{O}_{\bar{i}}$ generation during reperfusion. Cytochrome P-450 mixed function oxidases and NADPH cytochrome $c(\mathrm{P}-450)$ reduc-

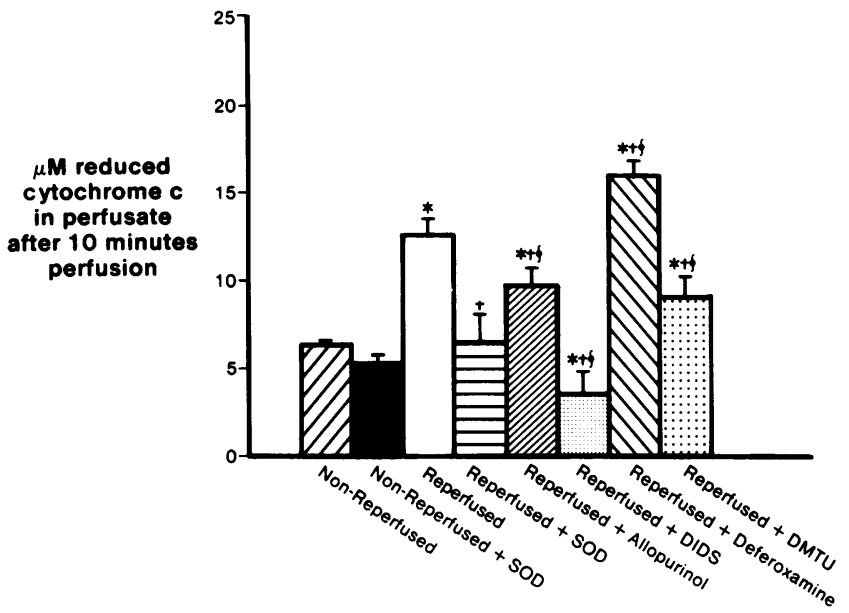

Figure 8. Reperfusion $\mathrm{O}_{\overline{2}}$ generation measured by cytochrome $c$ reduction. Reduction of the extracellular $\mathrm{O}_{\overline{2}}^{\overline{2}}$ detector succinylated ferricytochrome $c$ over $10 \mathrm{~min}$ of perfusion (micromoles cytochrome $c$ in perfusate) is significantly increased in lungs reperfused after $3 \mathrm{~h}$ of ischemia, compared with nonreperfused normal lungs. Injection of $25,000 \mathrm{U}$ SOD into the pulmonary artery just before reperfusion or addition of the anion channel blocker DIDS $(100 \mu \mathrm{M})$ to perfusate decreases cytochrome $c$ reduction to levels similar or even lower than in nonreperfused lungs. The xanthine oxidase inhibitor allopurinol $(1.5 \mathrm{mM})$ or the thiol DMTU $(45 \mathrm{mM})$ significantly decreases cytochrome $c$ reduction compared with reperfused lungs, but reduction remains elevated above that in normal lungs. Reduction in lungs treated with the iron chelator deferoxamine $(10 \mathrm{mM})$ is significantly higher than in untreated reperfused lungs. $n=4$ lungs in each group. ${ }^{*} P<0.01$ compared with nonreperfused lungs. ${ }^{\dagger} P<0.001$ compared with reperfused lungs. ${ }^{\S} P<0.01$ compared with reperfused lungs + SOD.

tase are responsible for much of the $\mathrm{O}_{\overline{2}}$ normally produced by microsomes, and thus might be sources of $\mathrm{O}_{\bar{z}}$ production during reperfusion injury (37). In this regard, it is interesting to note that allopurinol is a known inhibitor of P-450 metabolism $(38,39)$. Other potential microsomal sources of $\mathrm{O}_{\overline{2}}$ are peroxidases associated with AA metabolism (40), which have been hypothesized as sources of $\mathrm{O}_{\bar{z}}$ generated during reperfusion of ischemic brain (21). Finally, $\mathrm{O}_{\overline{2}}$ is a small but normal physiologic byproduct of aerobic mitochondrial metabolism at the NADH dehydrogenase step and from autooxidation of ubiquinone (41). The rate of mitochondrial $\mathrm{O}_{\overline{2}}^{\bar{z}}$ production is directly proportional to $\mathrm{O}_{2}$ tension and inversely proportional to the respiratory rate of the cell, increasing under conditions of low ADP but high substrate and $\mathrm{O}_{2}$ availability when the respiratory rate is slow and components of the respiratory chain are mostly reduced (41). These are the conditions that exist shortly after reperfusion of ischemic tissue, when substrate supply and $\mathrm{O}_{2}$ tension are restored, but ADP levels are low from catabolism during ischemia.

The mechanism whereby a large extracellular enzyme such as SOD (42) protects against reperfusion injury from intracellular generation of $\mathrm{O}_{\bar{z}}^{\bar{z}}$ is shown in Table II. Whereas active SOD protects from reperfusion injury, perfusion of lungs with $100 \mu \mathrm{M}$ DIDS prevents anion channel exit of $\mathrm{O}_{\overline{2}}^{\overline{2}}$ from intracellular sites of generation and blocks the protective effect of SOD in the extracellular medium. The lack of effective protection against reperfusion injury by SOD in DIDS-perfused lungs suggests that extracellular SOD reduces injury by con- 
Table II. Prevention of the Protective Effect of SOD by Anion Channel Blockade with DIDS

\begin{tabular}{|c|c|c|c|c|c|c|c|c|c|}
\hline \multirow[b]{2}{*}{ Time (minutes) } & \multicolumn{3}{|c|}{ Baseline } & \multirow[b]{2}{*}{$P_{\mathrm{pe} \max }$} & \multicolumn{5}{|c|}{ Reperfusion } \\
\hline & 0 & 2.5 & 5 & & 0 & 2.5 & 5 & 7.5 & 10 \\
\hline \multicolumn{10}{|l|}{$P_{\mathrm{pa}}(m m H g)$} \\
\hline Control & $14 \pm 0.9$ & $15 \pm 1$ & $15 \pm 1$ & $30 \pm 2$ & $24 \pm 3$ & $26 \pm 2$ & $28 \pm 2$ & $26 \pm 2$ & $25 \pm 2$ \\
\hline SOD & $10 \pm 3$ & $14 \pm 1$ & $14 \pm 1$ & $18 \pm 0.8^{*}$ & $18 \pm 0.8^{*}$ & $16 \pm 0.9^{*}$ & $15 \pm 1^{*}$ & $15 \pm 1^{*}$ & $15 \pm 1^{*}$ \\
\hline SOD + DIDS & $13 \pm 0.6$ & $13 \pm 0.6$ & $13 \pm 0.5$ & $20 \pm 0.8^{*}$ & $20 \pm 0.9^{*}$ & $15 \pm 0.7^{*}$ & $16 \pm 1^{*}$ & $16 \pm 1^{*}$ & $16 \pm 1^{*}$ \\
\hline DIDS & $12 \pm 0.8$ & $12 \pm 0.7$ & $12 \pm 0.8$ & $18 \pm 0.2^{*}$ & $16 \pm 1^{*}$ & $15 \pm 2^{*}$ & $14 \pm 2^{*}$ & $13 \pm 2^{*}$ & $14 \pm 3^{*}$ \\
\hline Allopurinol + DIDS & $15 \pm 0.6$ & $15 \pm 0.5$ & $15 \pm 0.5$ & $14 \pm 1^{*}$ & $23 \pm 1^{\ddagger}$ & $20 \pm 1^{*}$ & $18 \pm 1^{*}$ & $18 \pm 1^{*}$ & $17 \pm 1^{*}$ \\
\hline \multicolumn{10}{|l|}{$P_{\mathrm{T}}(m m H g)$} \\
\hline Control & $8 \pm 0.7$ & $8 \pm 0.7$ & $8 \pm 0.7$ & & $11 \pm 1$ & $16 \pm 0.9$ & $18 \pm 1$ & $21 \pm 2$ & $24 \pm 4$ \\
\hline SOD & $6 \pm 0.3$ & $7 \pm 0.3$ & $7 \pm 0.3$ & & $7 \pm 1$ & $9 \pm 0.8^{*}$ & $10 \pm 0.8^{\S}$ & $10 \pm 0.9^{*}$ & $11 \pm 0.8^{*}$ \\
\hline SOD + DIDS & $6 \pm 0.6$ & $6 \pm 0.7$ & $7 \pm 0.5$ & & $13 \pm 1$ & $17 \pm 2$ & $20 \pm 3$ & $23 \pm 4$ & $28 \pm 6$ \\
\hline DIDS & $8 \pm 0.8$ & $8 \pm 0.8$ & $8 \pm 0.8$ & & $12 \pm 1$ & $13 \pm 2^{\ddagger}$ & $14 \pm 2$ & $14 \pm 3$ & $19 \pm 8$ \\
\hline Allopurinol + DIDS & $6 \pm 0.3$ & $6 \pm 0.2$ & $6 \pm 0.2$ & & $6 \pm 0.4^{\ddagger}$ & $8 \pm 1^{*}$ & $9 \pm 2 *$ & $9 \pm 2 *$ & $10 \pm 2 *$ \\
\hline \multicolumn{10}{|l|}{$\Delta \mathbf{W}(g / \min )$} \\
\hline Control & & & $0.09 \pm 0.02$ & & & & & & $3.62 \pm 0.76$ \\
\hline SOD & & & $0.06 \pm 0.02$ & & & & & & $0.32 \pm 0.07^{\ddagger}$ \\
\hline SOD + DIDS & & & $0.09 \pm 0.04$ & & & & & & $4.52 \pm 1.15$ \\
\hline DIDS & & & $0.04 \pm 0.02$ & & & & & & $3.44 \pm 1.49$ \\
\hline Allopurinol + DIDS & & & $0.05 \pm 0.02$ & & & & & & $0.75 \pm 0.17^{\ddagger}$ \\
\hline
\end{tabular}

${ }^{*} P<0.001,{ }^{\ddagger} P<0.05,{ }^{\S} P<0.01$ compared with control. Values are mean $\pm \mathrm{SEM} ; P_{\mathrm{pa}}$, pulmonary artery pressure; $P_{\mathrm{T}}$, tracheal pressure; $\Delta \mathrm{W}$, rate of lung weight gain from edema formation; $P_{\mathrm{pa} \mathrm{max}}$, maximal pulmonary pressure during reperfusion; SOD, 25,000 U SOD; SOD + DIDS, SOD + $100 \mu \mathrm{M}$ DIDS; allopurinol + DIDS, allopurinol (1.5 mM) + DIDS (100 $\mu \mathrm{M})$; untreated control, 10 lungs; SOD, five lungs; SOD

+ DIDS, five lungs; DIDS, five lungs; allopurinol + DIDS, four lungs.

suming any extracellular $\mathrm{O}_{\overline{2}}$, thereby establishing a concentration gradient favorable for rapid diffusion of $\mathrm{O}_{\overline{2}}$ out of cells. When this diffusion is blocked, oxidant-mediated cell injury occurs, despite the presence of extracellular SOD. In contrast, allopurinol decreases $\mathrm{O}_{\overline{2}}$ production intracellularly at the site of generation and protects from reperfusion injury, even when DIDS blocks $\mathrm{O}_{\dot{2}}$ exit from cells.

Our studies have several potential clinical implications. Reperfusion pulmonary edema has recently been reported in man after pulmonary artery thromboendarterectomy in patients with unresolved pulmonary emboli (43). Reperfusion injury might play a role, as well, in acute pulmonary embolism, which could produce ischemia and subsequent reperfusion injury in the region of lung embolized. Also, reperfusion injury might be important as a magnification process for inflammation in the adult respiratory distress syndrome, in which perfusion of the pulmonary vasculature is occluded by vasoconstriction, microemboli, or in situ thromboses (44). Finally, our findings might prove helpful in preventing postoperative pulmonary edema after lung and heart-lung transplantation (45). If our success in preventing reperfusion injury in rabbit lungs can be applied to the design of an effective preservative solution, lung transplantation might become a more readily achievable therapeutic modality for patients with severe lung disease.

\section{Acknowledgments}

The authors gratefully acknowledge the assistance of Ms. Kay Terrell, Ms. Linda Watts, and Ms. Vicky Franke in preparation of this manuscript.
This work was supported by grants $\mathrm{OH}-02264$ from the National Institute of Occupational Safety and Health (NIOSH), and HL-01308, HL-37615, and HL-40665 from the National Institutes of Health.

\section{References}

1. McCord, J. M. 1985. Oxygen-derived free radicals in post-ischemic tissue injury. N. Engl. J. Med. 312:159-163.

2. Parks, D. A., and D. N. Granger. 1986. Xanthine oxidase: biochemistry, distribution and physiology. Acta. Physiol. Scand. (Suppl.) 548:87-99.

3. Cohen, G. 1985. The Fenton reaction. In CRC Handbook of Methods for Oxygen Radical Research. R. A. Greenwald, editor. CRC Press, Inc., Boca Raton, FL. 55-64.

4. Weiss, S. J. 1986. Oxygen, ischemia and inflammation. Acta. Physiol. Scand. 126(Suppl. 548):9-37.

5. Aust, S. D., and B. C. White. 1985. Iron chelation prevents tissue injury following ischemia. Adv. Free Rad. Biol. Med. 1:1-17.

6. Paller, M. S., J. R. Hoidal, and T. F. Ferris. 1984. Oxygen free radicals in ischemic acute renal failure in the rat. J. Clin. Invest. 74:1156-1164.

7. Zweier, J. R. 1988. Measurement of superoxide-derived free radicals in the reperfused heart. Evidence for a free radical mechanism of reperfusion injury. J. Biol. Chem. 263:1353-1357.

8. Granger, D. N., G. Rutili, and J. M. McCord. 1981. Role of superoxide radicals in intestinal ischemia. Gastroenterology. 81:22-29.

9. Marubayashi, S., K. Dohi, H. Ezaki, K. Yamada, and T. Kawasaki. 1983. Preservation of ischemic liver cells-prevention of damage by coenzyme Q-10. Transplant Proc. 15:1297-1299.

10. Sanfrey, H., G. B. Bulkley, and J. L. Cameron. 1985. The pathogenesis of acute pancreatitis. The source and role of oxygen derived free radicals in three different experimental models. Ann. Surg. 201:633-639. 
11. Manson, P. N., R. M. Anthenelli, M. J. Im, G. B. Bulkley, and J. E. Hoopes. 1983. The role of oxygen-free radicals in ischemic injury in island skin flaps. Ann. Surg. 198:87-90.

12. Jackson, R. M., C. F. Veal, C. B. Alexander, A. L. Brannen, and J. D. Fulmer. 1988. Reexpansion pulmonary edema. A potential role for free radicals in its pathogenesis. Am. Rev. Respir. Dis. 137:11651171.

13. Bishop, M. J., E. S. Boatman, T. D. Ivey, J. P. Jordan, and F. W. Cheney. 1986. Reperfusion of ischemic dog lung results in fever, leukopenia, and lung edema. Am. Rev. Respir. Dis. 134:752-756.

14. Fisher, A. B., and C. Dodia. 1981. The lung as a model for evaluation of critical intracellular $\mathrm{PO}_{2}$ and $\mathrm{PCO}_{2}$. Am. J. Physiol. 241:E47-50.

15. Krebs, H. A., and K. Henseleit. 1932. Untersuchungen uber die harustoffbildung im tierkorper. Hoppe-Seyler's Z. Physiol. Chem. 210:33-66.

16. Farrukh, I. S., J. R. Michael, W. R. Summer, N. Franklin, N. F. Adkinson, and G. H. Gurtner. 1984. Thromboxane induced pulmonary vasoconstriction: involvement of calcium. J. Appl. Physiol. Respir. Environ. Exercise Physiol. 58:38-44.

17. Gutterige, J. M. C., R. Richmond, and B. Halliwell. 1979. Inhibition of the iron catalyzed formation of hydroxyl radicals from superoxide and lipid peroxidation by desferrioxamine. Biochem. $J$. 184:469-472.

18. Fox, R. B. 1984. Prevention of granulocyte-mediated oxidant lung injury in rats by a hydroxyl radical scavenger, dimethylthiourea. J. Clin. Invest. 74:1456-1464.

19. Bernard, G. R., W. D. Lucht, M. E. Niedermeyer, J. R. Snapper, M. L. Ogletree, and K. L. Brigham. 1984. Effect of N-acetylcysteine on the pulmonary response to endotoxin in awake sheep and upon in vitro granulocyte function. J. Clin. Invest. 73:1772-84.

20. Heikkila, R. E. 1985. Inactivation of superoxide dismutase by diethyldithiocarbamate. In CRC Handbook of Methods for Oxygen Radical Research. R. A. Greenwald, editor. CRC Press, Inc., Boca Raton, FL. 387-390.

21. Kontos, H. A., E. P. Wei, E. F. Ellis, L. W. Jenkins, J. T. Povlishock, G. T. Rowe, and M. L. Hess. 1985. Appearance of superoxide anion radical in cerebral extracellular space during increased prostaglandin synthesis in cats. Circ. Res. 57:142-151.

22. Auclair, C., and E. Viosin. 1985. Nitroblue tetrazolium reduction. In CRC Handbook of Methods for Oxygen Radical Research. R. A. Greenwald, editor. CRC Press, Inc., Boca Raton, FL. 276-287.

23. Kuthan, H., V. Ullrich, and R. W. Estabrook. 1982. A quantitative test for superoxide radicals produced in biological systems. Biochem. J. 203:551-558.

24. Habeeb, A. F. S. A. 1966. Determination of free amino groups in proteins by trinitrobenzenesulfonic acid. Anal. Biochem. 14:328336.

25. Wieth, J. O., O. S. Anderson, J. Brahm, P. J. Bjerrum, and C. L. Borders, Jr. 1982. Chloride-bicarbonate exchange in red blood cells: physiology of transport and chemical modification of binding sites. Philos. Trans. R. Soc. Lond. B Biol. Sci. 299:383-399.

26. Lynch, R. E., and I. Fridovich. 1978. Permeation of the erythrocyte stroma by superoxide radical. J. Biol. Chem. 253:4697-4699.

27. Cabantchik, Z. I., and A. Rothstein. 1974. Membrane proteins related to anion permeability of human red blood cells. J. Membr. Biol. 15:207-226.
28. Snedecor, G. E., and W. G. Cochran. Statistical Methods. 7th ed. Iowa State University Press, Ames, IA. 256-257.

29. Snedecor, G. E., and W. G. Cochran. Statistical Methods. 7th ed. Iowa State University Press, Ames, IA. 158-160.

30. Duncan, D. B. 1975. $t$-tests and intervals for comparison suggested by the data. Biometrics. 31:339-359.

31. Tate, R. M., H. G. Morris, W. R. Schroeder, and J. E. Repine. 1984. Oxygen metabolites stimulate thromboxane production and vasoconstriction in isolated saline-perfused rabbit lungs. J. Clin. Invest. 74:608-613.

32. Moorhouse, P. C., M. Grootveld, B. Halliwell, J. G. Quinlan, and M. C. J. Gutteridge. 1987. Allopurinol and oxypurinol are hydroxyl radical scavengers. FEBS (Fed. Eur. Biochem. Soc.) Lett. 213:313-319.

33. Halliwell, B. 1985. Use of desferrioxamine as a "probe" for iron-dependent formation of hydroxyl radicals. Evidence for a direct reaction between desferal and the superoxide radical. Biochem. Pharmacol. 34:229-233.

34. Nayini, N. R., B. C. White, S. D. Aust, R. R. Huang, R. J. Indrieri, A. T. Evans, H. Bialek, W. A. Jacobs, and J. Komara. 1985. Postischemic iron delocalization and malondialdehyde production in the brain following prolonged cardiac arrest. J. Free Rad. Biol. Med. 1:111-116.

35. Thomas, C. E., L. A. Morehouse, and S. D. Aust. 1985. Ferritin and superoxide-dependent lipid peroxidation. J. Biol. Chem. 260:3275-3280.

36. Fridovich, I. 1985. Cytochrome $c$. In CRC Handbook of Methods for Oxygen Radical Research. R. A. Greenwald, editor. CRC Press, Inc., Boca Raton, FL. 213-215.

37. Chance, B., H. Sies, and A. Boveris. 1979. Hydroperoxide metabolism in mammalian organs. Physiol. Rev. 59:527-605.

38. Vessell, E. S., G. T. Passananti, and F. E. Greene. 1970. Impairment of drug metabolism in man by allopurinol and nortryptyline. N. Engl. J. Med. 283:1484-1488.

39. Tjandramage, T. B., S. A. Cicinell, Z. H. Israeli, J. M. Pevel, P. G. Dayton, T. F. Yu, and A. G. Gutman. 1972. Observations on the disposition of probenecid in patients receiving allopurinol. Pharmacology. 8:259-272.

40. Marnett, L. J. 1984. Hydroperoxide-dependent oxidations during prostaglandin biosynthesis. In Free Radicals in Biology. Vol. 6. W. A. Pryor, editor. Academic Press, Inc., New York. 63-69.

41. Forman, H., and A. Boveris. 1982. Superoxide radical and hydrogen peroxide in mitochondria. In Free Radicals in Biology. Vol. 5. W. A. Pryor, editor. Academic Press, Inc., New York. 65-90.

42. Freeman, B. A., S. L. Young, and J. D. Crapo. 1983. Liposome-mediated augmentation of superoxide dismutase in endothelial cells prevents oxygen injury. J. Biol. Chem. 58:12534-12543.

43. Levinson, R. M., D. Shure, and K. M. Moser. 1986. Reperfusion pulmonary edema after pulmonary artery thromboendarterectomy. Am. Rev. Respir. Dis. 134:1241-1245.

44. Greene, R., W. M. Zapol, M. T. Snider, L. Reid, R. Snow, R. S. O'Connell, and R. A. Novelliue. 1981. Early bedside detection of pulmonary vascular occlusion during acute respiratory failure. Am. Rev. Respir. Dis. 124:593-601.

45. Reitz, B. A., J. L. Wallwork, S. A. Hunt, J. L. Pennock, M. E. Billingham, P. E. Oyer, E. B. Stinson, and N. E. Shumway. 1982. Heart-lung transplantation. Successful therapy for patients with pulmonary vascular disease. $N$. Engl. J. Med. 306:557-564. 